\title{
Introducción: Software libre y código abierto: experiencias innovadoras en bibliotecas y centros de información
}

\author{
Cristián Valenzuela Urra \\ Universidad de Playa Ancha. Facultad de Ciencias Sociales. Departamento de Ciencias \\ de la Documentación, Chile \\ cvalen@upla.cl \\ Danilo Reyes Lillo \\ Universidad de Playa Ancha. Facultad de Ciencias Sociales. Departamento de Ciencias \\ de la Documentación, Chile \\ danilo.reyes@upla.cl

\section{Sergio Oliveros Castro} \\ Universidad de Playa Ancha. Facultad de Ciencias Sociales. Departamento de Ciencias \\ de la Documentación, Chile \\ Sergio.oliveros.castro7@gmail.com
}

Cita sugerida: Valenzuela Urra, C., Reyes Lillo, D. y Oliveros Castro, S. (2018). Introducción: Software libre y código abierto: experiencias innovadoras en bibliotecas y centros de información. Palabra Clave (La Plata), 8(1), e054. https://doi.org/10.24215/18539912e054 


\section{Introducción: Software libre y código abierto: experiencias innovadoras en bibliotecas y centros de información}

Introduction: Free and Open Source software: innovative experiences in libraries and information centers

Cristián Valenzuela Urra

Universidad de Playa Ancha. Facultad de Ciencias Sociales.

Departamento de Ciencias de la Documentación, Chile

cvalen@upla.cl

Danilo Reyes Lillo

Universidad de Playa Ancha. Facultad de Ciencias Sociales.

Departamento de Ciencias de la Documentación, Chile

Sergio Oliveros Castro

Universidad de Playa Ancha. Facultad de Ciencias Sociales.

Departamento de Ciencias de la Documentación, Chile

En los inicios del desarrollo de las computadoras, lo que principalmente comercializaban las grandes empresas de desarrollo eran las máquinas (hardware) y no los programas asociados (software), porque se asumía que eran elementos intangibles que el hardware necesitaba para operar (Alonso Puelles y D'Antonio Maceiras, 2015).

Sin embargo, a partir del año 1970, IBM empezó a comercializar el software y otras empresas continuaron transformando este elemento intangible en un producto comercial. Al mismo tiempo, el código fuente de UNIX era puesto a disposición de la universidad de forma gratuita, procedente de los laboratorios Bell de ATT.

A pesar de que esta dualidad de software propietario y software libre pareciese tener directa relación con el precio o costo comercial de algún programa computacional (software gratuito y software comercial), esta dualidad resulta fundamentalmente ética, donde la palabra libre no se vincula al valor, sino a las libertades que debe cumplir una aplicación para considerarse software libre (Torricella Morales, Lee Tenorio y Huerta Espinosa, 2008). Estas libertades son planteadas por Richard Stallman en 1986 (El Sistema Operativo GNU, 2018):

- Libertad 0, usar el software con cualquier propósito.

- Libertad 1, permitir el estudio del funcionamiento el software y su adaptación a las necesidades del usuario.

- Libertad 2, permitir distribución de copias a terceros para fomentar la creación de comunidades.

- Libertad 3, permitir hacer mejoras en los softwares para que toda la comunidad se pueda beneficiar de los nuevos desarrollos.

Este dilema ético relacionado con la libertad no está ajeno al contexto de las bibliotecas y los centros de información. Al contrario, en múltiples declaraciones IFLA se ha referido al concepto de libertad como valor fundamental en el quehacer bibliotecario. Bajo esta premisa, como señala Zurita Sánchez (2008), es posible entender la utilización del software libre:

Como una herramienta abierta y flexible para bibliotecas y centros de información, cuya aplicación puede ir más allá de labores cotidianas de administración y prestación de servicios. En otras palabras, el software libre presenta una serie de 
oportunidades para el gremio bibliotecario en tanto que permite el desarrollo y la creación de servicios de información a bajo costo y con un espíritu de colaboración (p. 10).

En este mismo sentido UNESCO reconoce la importancia del software libre para el desarrollo de las diferentes comunidades nacionales, regionales y locales. Considera que estas herramientas informáticas facilitan la cooperación internacional entre los usuarios y los desarrolladores, permiten la utilización de estándares abiertos, admiten la creación de documentación técnica en los idiomas propios de cada comunidad, facilitan la colaboración en la formulación e implementación de políticas públicas y, por último, invitan a participar y defender las propuestas y los postulados que defiende este movimiento (Aladejo, Franco, Morales y Torrico, 2010).

Por otra parte, la industria de la tecnología bibliotecaria ha sufrido importantes modificaciones con fusiones horizontales y verticales de empresas, quedando cada vez menos nombres propios de organismos que ofertan software para centros de información en el mercado y con la integración de nuevas sinergias (Breeding, 2017).

Lo anterior nos permite revisitar las ventajas del software libre en un contexto donde el mercado se torna árido: 1) ofrece adaptación a la necesidad del usuario debido a la apertura de su código fuente, 2) no precisa de inversiones en licencias o suscripciones anuales por sus canales de distribución, 3) permite compartir experiencias de uso con otros usuarios y construir comunitariamente las mejoras de cada desarrollo y, 4) otorga un mayor control sobre los servicios que se ofrecen a través del software.

En paralelo a estas 4 características, el software libre, por su naturaleza tiende a incentivar el trabajo colaborativo y cooperativo, manifestado en el establecimiento de comunidades de usuarios que van dando forma y actualización a los diferentes proyectos que sean de su interés o respondan a las necesidades de éstos. Estas actualizaciones y el desarrollo de nuevos programas tienen el componente de la libre distribución, copia y modificación, lo cual significa que emplean un modelo contrario al de autoría controlada, hecho que, en alguna medida, favorece a la superación de la piratería: el producto pertenece a todos los que lo necesiten. A estos elementos hay que sumarle el progreso y profundización informático, que conduce al perfeccionamiento y la experimentación de nuevas funcionalidades en los diferentes programas de código abierto.

De esta forma, el aumento en el uso de software libre en bibliotecas y centros de información va a depender de la manera en que la comunidad bibliotecaria comience a adquirir conocimiento sobre dichos softwares y pueda participar con otros profesionales usando, desarrollando y compartiendo experiencias (Arriola Navarrete, Tecuatl Quechol y González Herrera, 2011).

En este número de la revista Palabra Clave, cuya temática está centrada en el uso de software libre en bibliotecas y centros de información, los lectores podrán encontrar textos que abordan distintas experiencias y aplicaciones de tecnologías de la información y la comunicación libres para el desarrollo de distintas labores, desde tecnologías de linked data hasta la vigilancia científico tecnológica mediante el acceso libre.

\section{REFERENCIAS}

Aladejo, M., Franco, L., Morales., y Torrico, V. (2010). Importancia del software libre según la UNESCO. Recuperado de https://es.slideshare.net/lynda1302/importancia-del-software-libre-segn-la-unesco

Alonso Puelles, A., y D’Antonio Maceiras, S. (2015). El software libre y el Open Knowledge como comunidades de conocimiento paradigmáticas. Utopia y Praxis Latinoamericana, 20(69), 83-92.

Arriola Navarrete, O., Tecuatl Quechol, G., y González Herrera, G. (2011). Software propietario vs software libre: una evaluación de sistemas integrales para la automatización de bibliotecas. Investigación bibliotecológica, 25(54), 37-70. Recuperado de http://www.scielo.org.mx/scielo.php? script=sci_arttext\&pid=S0187-358X2011000200003\&lng=es\&nrm=iso 
Breeding, M. (2017). Informe de sistemas de bibliotecas 2017. Visiones competitivas de tecnología, software abierto y flujo de trabajo. El profesional de la información, 26(3), 543-557.

El Sistema Operativo GNU. (2018). La definición de Software Libre. Recuperado de https://www.gnu.org/philosop hy/free-sw.es.html

Torricella Morales, R., Lee Tenorio, F. y Huerta Espinosa, V. (2008). Acceso abierto y software libre: premisas para la independencia tecnológica. ACIMED, 17(2). Recuperado de http://scielo.sld.cu/scielo.php? script $=$ sci_arttext\&pid $=$ S1024-94352008000200009\&lng=es\&nrm=iso

Zurita Sánchez, J. M. (2008). Software libre: una alternativa para la gestión de información en bibliotecas. Revista Iberoamericana de Sistemas, Cibernética e Informática, 2008, 5(1), 7-13. Recuperado de http:// eprints.rclis.org/13294/ 